\title{
In memory of Professor Alexey V. Borisov (27.03.1965-24.01.2021)
}

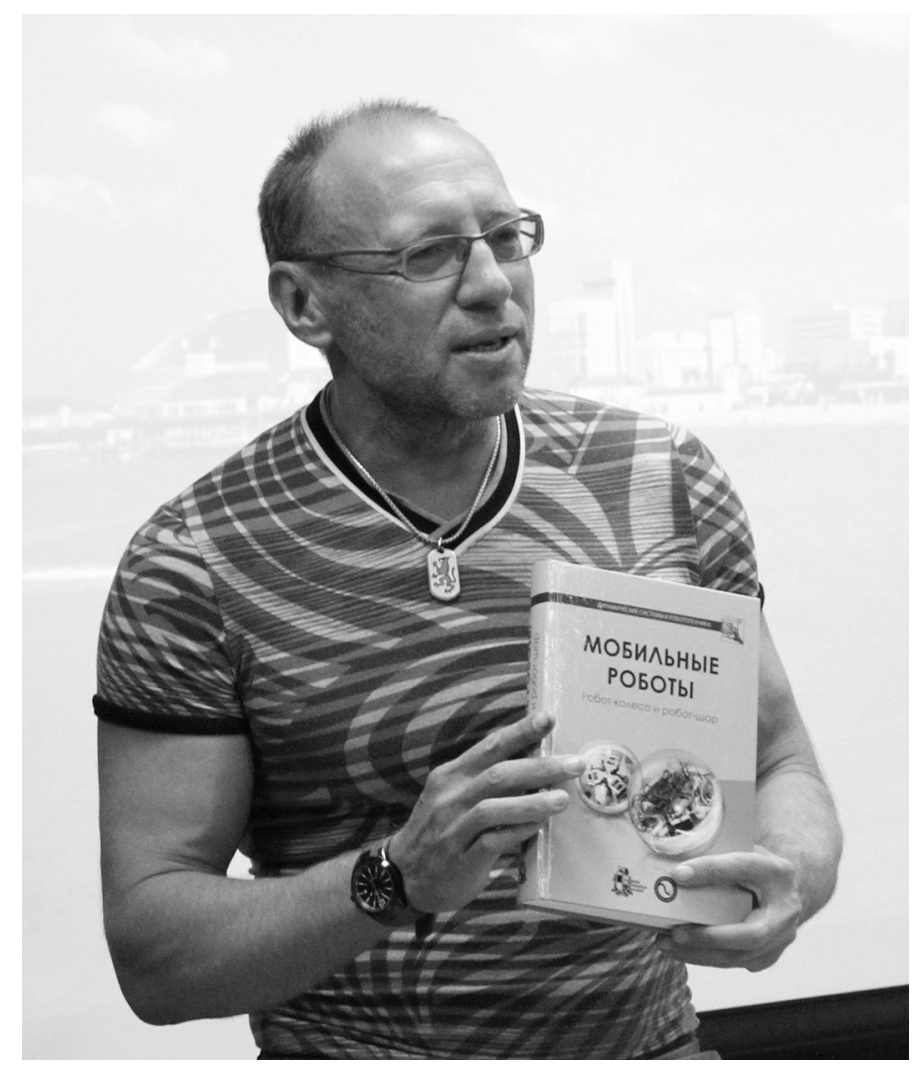

On January 24, the co-founder and editor-in-chief of the Russian Journal of Nonlinear Dynamics (previously called "Nelineinaya Dinamika"), Professor Alexey Borisov passed away at the age of 55 . He lived a short but very intense and fruitful life ${ }^{1}$. His research, editorial and organizational activities, contributions and achievements are greatly appreciated by the scientific community. We will always remember him as an esteemed colleague, a great researcher and an outstanding person.

\footnotetext{
${ }^{1}$ For details on the life and career of Professor Borisov, see the obituary published in RCD (In Memory of Professor Alexey V. Borisov (27.03.1965-24.01.2021), Regular and Chaotic Dynamics, 2021, vol. 26, no. 2, pp. 113-118) and the website of the Institute of Computer Science (http://ics.org.ru/staff/ detail/23-alexey_borisov).
} 